Document downloaded from:

http://hdl.handle.net/10251/125121

This paper must be cited as:

Andres, B.; Poler, R.; Saari, L.; Arana, J.; Benaches, J.; Salazar, J. (2018). Optimization Models to Support Decision-Making in Collaborative Networks: A Review. Lecture Notes in Management and Industrial Engineering. 249-258. https://doi.org/10.1007/978-3-319-584096_28

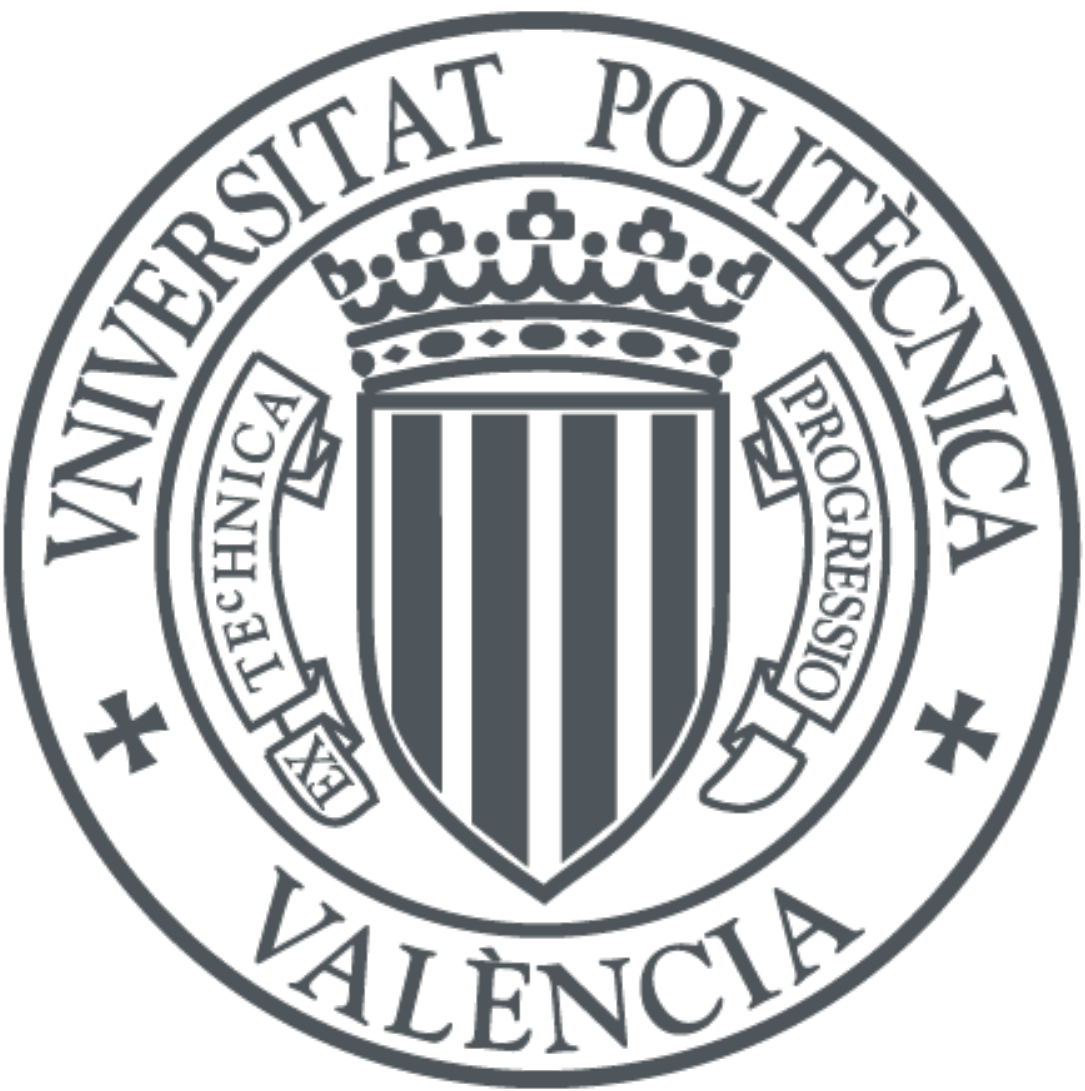

The final publication is available at

http://doi.org/10.1007/978-3-319-58409-6_28

Copyright Springer

Additional Information 


\title{
Optimization models to support decision- making in collaborative networks: A review
}

\author{
Andres B' ${ }^{1}$, Poler $\mathbf{R}^{2}$, Saari L ${ }^{3}$, Arana $\mathbf{J}^{4}$, Benaches $\mathbf{J V}^{5}$, Salazar $\mathbf{J}^{6}$
}

\begin{abstract}
Enterprises, especially SMEs, are increasingly aware of belonging to Collaborative Networks $(\mathrm{CN})$, due to the competitive advantages associated to deal with markets globalization and turbulence. The participation in $\mathrm{CN}$ involves enterprises to perform collaborative planning along all the processes established with the CN partners. Nevertheless, the access of SMEs to optimisation tools, for dealing with collaborative planning, is currently limited. To solve this concern, novel optimisation approaches have to be designed in order to improve the integrated planning in CN. In order to deal with this problem, this paper proposes a baseline to identify current enterprise needs and literature solutions in the replenishment, production and delivery collaborative planning, as a part of the H2020 Cloud Collaborative Manufacturing Networks (C2NET) research project. The
\end{abstract}

${ }^{1}$ Beatriz Andres (e-mail: $₫$ bandres@cigip.upv.es)

Research Centre on Production Management and Engineering (CIGIP). Escuela Politécnica Superior de Alcoy, Universitat Politècnica de València (UPV). Centre d'Innovació i Investigació. Calle Alarcón, 03801 Alcoy, Spain

${ }^{2}$ Raul Poler (e-mail: rpoler@cigip.upv.es)

Research Centre on Production Management and Engineering (CIGIP). Escuela Politécnica Superior de Alcoy, Universitat Politècnica de València (UPV). Centre d'Innovació i Investigació. Calle Alarcón, 03801 Alcoy, Spain

${ }^{3}$ Leila Saari (e-mail: leila.saari@vtt.fi)

VTT Technological research centre of VTT Ltd., Kaitoväylä 1, FI-90570 OULU, Finland.

${ }^{4}$ Joseba Arana (e-mail: jmarana@ikerlan.es)

IK4-IKERLAN. Po .J.Ma . Aizmendiarriera, 20500 Arrasate-Mondragón.

${ }^{5}$ Jose-Vicente Benaches (e-mail: dirfab@novatecgroup.com)

NOVATEC GROUP.Polígono Industrial Los Vientos, Carrer Gregal, 12C, 46119 Nàquera,

Valencia.

6Javier Salazar (e-mail: javier.salazar@faurecia.com)

FAURECIA Exterior Systems Spain S.A. Poligono Industrial Juan Carlos I, Av. de la Foia, 4, 46440 Almussafes, Valencia. 
main gaps found between the literature reviewed and the enterprises' needs are presented and discussed.

Keywords: collaborative networks; collaborative processes; production planning; industrial optimisation needs;

\section{Introduction}

Collaborative networks are embedded in continuously changing environments that affect to demand changes, disruptions, uncertainties, etc. Internal enterprises plans and collaborative planning is affected by these changes. The main goal of current research is to provide appropriate optimisation and automated approaches to deal with the collaborative planning, providing affordable solutions to SMEs willing to collaborate. To this regard, the identification of contributions, provided in the literature, is considered a first step to perform in order to identify adequate algorithms and simulation procedures that allow SMEs to collaboratively establish replenishment, production and delivery planning processes. Affordable tools (in terms of cost, usability, light weight and easy to use tools) are required to help SMEs to overcome the current economic crisis and to enhance their competitiveness in the global economy.

The work described in this paper is framed in C2NET H2020 project (20152018) that will implement a Cloud Platform for supporting the SMEs supply network optimisation of manufacturing and logistic assets based on collaborative demand, production and delivery plans. C2NET Project will provide a scalable realtime architecture, platform and software to allow the supply network partners to (i) master complexity and data security of the supply network, (ii) store and share product, process and logistic data, (iii) optimise the manufacturing assets by the collaborative computation of production plans, (iv) optimise the logistics assets through efficient delivery plans and (v) render the complete set of supply chain management information on the any digital mobile device (PC, tablets, smartphones) of decision makers enabling them to monitor, visualise, control, share and collaborate.

To cope with the objective of this paper, the paper is organised as follows: Section 2 introduces the C2NET project, focusing on the automotive pilot, belonging to the automotive sector. In Section 3 a state of the art of the contributions addressing the replenishment, production and distribution collaborative planning is given. The review will allow identifying the gaps between the literature and the industry real needs. Finally, Section 4 discusses the conclusions. 


\section{Automotive pilot in Cloud Collaborative Manufacturing Networks Project}

C2NET project has the purpose to connect the Industrial, the Research and the Development perspectives. To this end four industrial Pilots are considered in the project, belonging to different industrial sectors (automotive, dermo-cosmetics, metalworking SMEs and OEM production of hydraulic and lubrication systems). This paper is going to focus in Automotive Pilot to study the needs that the enterprises belonging to this pilot have in their production plans, and how the literature plans cover the potential integration of collaborative replenishment, production and delivery plans.

The automotive pilot is framed in the automotive industrial sector and deals with collaborative production planning and synchronised replenishment of car components. The studied pilot consists of the first and second-tiers fully dedicated tot the car assembly. The first-tier supplier will use the C2NET cloud infrastructure, platform and software to perform collaborative production, replenishment planning and capacity shared with the second- tier suppliers of materials for car interior components to be supplied to the OEM. Enterprises of automotive pilot will share relevant information and will use the C2NET advanced algorithms to optimise production, supply and replenishment plans.

The automotive pilot takes as main input the 6 months demand release, the 7 days massive and the daily call-in (DCI) sent by the OEM to the first-tier. Considering these inputs, C2NET optimisation and simulation algorithms will automatically calculate (i) the first-tier car components production plans, and (ii) the firsttier parts requirements planning, which are the input for the Demand Plan of second-tier. Taking into account the second-tier capacities and current stock levels, C2NET will calculate the second-tier parts production plans and the materials requirements planning with the goal of optimising the manufacturing and logistics assets. Production, replenishment and distribution plans will be calculated with the goal of optimising the logistics assets of automotive pilot. C2NET will provide online re-calculations when changing market conditions or manufacturing situations and continuously update the plans taking into account the actual or current production, stocks and deliveries status.

The current research work allows identifying the gaps between the literature contributions and the automotive pilot needs, regarding the establishment of collaborative plans to support the decision-making in the establishment of collaborative source, make and delivery processes along the supply network (see Figure 1).

From the collaborative manufacturing and logistics processes identified in the enterprises belonging to the automotive pilot of C2NET project, a thorough review of current state of art of optimisation algorithms and simulation procedures used to solve related manufacturing processes problems, especially in the frame of collaborative processes, is made. As a result of this activity, a deep understanding of the different optimisation and simulation approaches existing in the literature is ob- 
tained. This knowledge will be considered as the main input to identify the gaps between the enterprises needs when dealing with their plans and the contributions that propose the literature to overcome this needs.

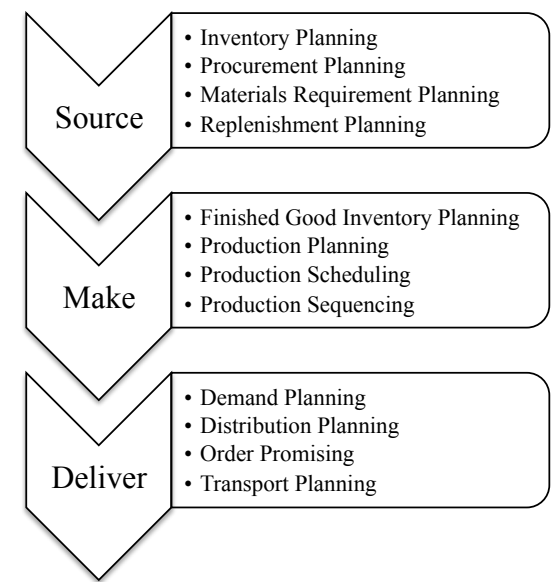

Figure 1. SCOR classification for industrial plans (based on: Supply Chain Council, 2012)

\section{Collaborative Network processes optimisation}

Research in optimisation solutions has been a very active field in the last decades. One of the most successful application areas has been the planning and scheduling of operational manufacturing processes, trying to optimise cost, resource allocation, delivery time, etc. Authors such as Billington et al. (1983), Escudero (1994), McDonald and Karimi (1997), Karimi and McDonald (1997), Rota et al. (1997), Clark (2003), Giglio and Minciardi (2003), Chen and Lee (2004), Lim et al. (2005), Yenisey (2006), Noori et al. (2008) and Alemany et al. (2010), among others, have addressed the optimisation of production systems through different mathematical programming approaches in a deterministic context. In addition, intelligent modelling and heuristic modelling approaches have been proposed as bridging techniques between the problems that theoretical optimisation techniques can handle and real world problems. Hernandez et al. (2014) developed multiagent negotiation based algorithms to support the collaborative supply chain planning process using intelligent modelling and heuristic modelling approaches. Here, those based on fuzzy mathematical programming models (Mula et al. 2010) have been developed for production planning problems under uncertainty. For an extensive review, Mula et al. (2006) is interesting reference in this field.

Which kind of technique is better for what kind of problems is controversial and is the source of much research. Real-life enterprise optimisation problems, as for example planning and scheduling, often need both linear and non-linear con- 
straints and may involve hundreds/thousands of (real/integer/binary) variables and constraints, and are difficult to tackle with generic algorithms.

\subsection{Production Planning: Make}

Production planning is associated with the plan Make view identified in the SCOR views (Supply Chain Council, 2012), and deals with the amounts of items to be produced per periods in a planning horizon. The main input data is the demand (customers orders or demand forecast). The production use limited own resources, which will define the solutions space. The goal is to obtain Production Plans, which minimise or maximise selected objectives. Production plans can be arranged considering three different levels of production (Figure 1):

- Make/Production Planning: Plan that deals with the allocation of assets to production tasks, determine the quantity of production, inventory and work force levels in order to satisfy the planned or actual demand. Production planning concerns the required level of production in a specified time horizon;

- Make/Production Scheduling: Given a set of due dates, demands for products at these dates, and several operational and topological constraints, this Plan deals with the start and end times of individual products and machine assignments. Scheduling model includes lot sizing models and machine scheduling models. Production scheduling concerns the allocation of finite resources to meet the demand requirements, paying heed to constraints such as capacity, precedence and start and due dates;

- Make/Production Sequencing: Plan that deals with the resource level ordering of jobs on a shared workstation. Production Sequence Plan is dependent of sequence setup costs and impossible restrictions in terms of the order of jobs.

Table 1 presents the matches between the Automotive industrial pilot optimization needs and Make plans found in literature. Each row presents a reference with industrial optimisation case and algorithm. Inputs were classified in six input data $\left(I d_{i}\right)$ types: $I d_{1}$ : Demand, $I d_{2}$ : Inventory, $I d_{3}$ : Capacity, $I d_{4}$ : Production Time, $I d_{5}$ : Set-up and $I d_{6}$ : Bill Of Materials (BOM). Objectives were arranged $\left(O_{j}\right)$ into three types: $O_{1}$ : Production cost minimisation, $O_{2}$ : Profit maximisation, $O_{3}$ : Setup minimisation. Finally, the outputs $\left(O d_{k}\right)$ were groped in four classes: $O d_{1}$ : Products to produce, $\mathrm{Od}_{2}$ : Backorders, $\mathrm{Od}_{3}$ : Machine assignation and $\mathrm{Od}_{4}$ : Extra time. Each $\mathrm{X}$ in the table represents a match between the industrial optimisation parameter and algorithm in literature. The algorithm types considered are classified considering the following taxonomy: AO optimisation algorithm, AM metaheuristic algorithm and $\mathrm{AH}$ heuristic algorithm. 
Table 1 Mapping between Pilot 1 optimisation needs and Make plans in the literature

\begin{tabular}{|c|c|c|c|c|c|c|c|c|c|c|c|c|c|c|}
\hline Automotive pilot & \multicolumn{6}{|c|}{ Input Data } & \multicolumn{3}{|c|}{ Objectives } & \multicolumn{4}{|c|}{ Output Data } & \multirow{2}{*}{$\begin{array}{c}\text { Algorithm } \\
\text { Type }\end{array}$} \\
\hline Plans Needs & $\mathrm{Id}_{1}$ & $\mathrm{Id}_{2}$ & $\mathrm{Id}_{3}$ & $\mathrm{Id}_{4}$ & $\mathrm{Id}_{5}$ & $\mathrm{Id}_{6}$ & $\mathrm{O}_{1}$ & $\mathrm{O}_{2}$ & $\mathrm{O}_{3}$ & $\mathrm{Od}_{1}$ & $\mathrm{Od}_{2}$ & $\mathrm{Od}_{3}$ & $\mathrm{Od}_{4}$ & \\
\hline McDonald and Karimi (1997) & $\mathrm{X}$ & $\mathrm{X}$ & $\mathrm{X}$ & & $\mathrm{X}$ & $\mathrm{X}$ & $\mathrm{X}$ & $\mathrm{X}$ & & $\mathrm{X}$ & $\mathrm{X}$ & & & AO/ Simplex \\
\hline Escudero (1994) & $\mathrm{X}$ & $\mathrm{X}$ & $\mathrm{X}$ & $\mathrm{X}$ & & $\mathrm{X}$ & & $\mathrm{X}$ & & $\mathrm{X}$ & $\mathrm{X}$ & & & $\begin{array}{l}\mathrm{AO} / \text { Decompo- } \\
\text { sition strategy }\end{array}$ \\
\hline Gupta and Magnusson (2005) & $\mathrm{X}$ & $\mathrm{X}$ & $\mathrm{X}$ & & $\mathrm{X}$ & & & & $\mathrm{X}$ & $\mathrm{X}$ & & & & AO/ Simplex \\
\hline Franz et al. (2014) & $\mathrm{X}$ & & & $\mathrm{X}$ & & & & & & $\mathrm{X}$ & & $\mathrm{X}$ & & $\begin{array}{c}\mathrm{AM} / \mathrm{Tabu} \\
\text { Search }\end{array}$ \\
\hline Gansterer, M. (2015) & $\mathrm{X}$ & $\mathrm{X}$ & $\mathrm{X}$ & $\mathrm{X}$ & & $\mathrm{X}$ & & & & $\mathrm{X}$ & $\mathrm{X}$ & & & $\begin{array}{l}\text { AH/ Variable } \\
\text { Neighbourhood } \\
\text { Search }\end{array}$ \\
\hline
\end{tabular}

\subsection{Replenishment, production and distribution collaborative planning}

Source \& Make \& Deliver (S\&M\&D) plan is characterised the integration of plans, of the collaborative network partners, that deals with (i) the procurement of goods and services, by computing the amount of items to be ordered per periods in a planning horizon considering the material needs, the limited resources of the supplier (ii) the transformation of products into finished goods and (iii) the distribution of finished goods and services to meet planned or actual demands, computing the amount of items to be delivered per periods in a planning horizon considering the customers' orders, and the delivery limited resources (own, from the customer or from a third party). Automotive pilot proposes the envisioned collaborative plan regarding $\mathrm{S} /$ Replenishment \& $\mathrm{M} /$ Production Planning \& $\mathrm{D} /$ Distribution Planning to deal with sourcing considerations for replenishments, production facilities, and distribution centres, over the time periods of the planning horizon. Inputs were classified in eight input data: Id1 Demand, Id2 Inventory, Id3 Capacity, Id4 Production Time, Id5 Setup, Id6 BOM, Id7 Transport batch minimum Id8 Transport Capacity. Objectives were arranged $\left(O_{j}\right)$ into four types: O1 Production cost min, O2 Profit max, O3 Setup min, O4 Transport/distribution cost min. Finally, the outputs $\left(O d_{k}\right)$ were groped in six classes: Od1 Products to produce, Od2 Backorders, Od3 Machine assignation, Od4 Extra time, Od5 Raw material to purchase, Od6 Product quantity to transport. Allocation decision of final goods to production lines are defined with a limited capacity, but also with the determination of lot sizing. Following the structure defined in Table 1, Table 2 presents the mapping between the industry optimisation needs and the combined replenishment, production and distribution plans found in literature. 
Table 2 Mapping between Automotive pilot optimisation needs and SMD plans in the literature

\begin{tabular}{|c|c|c|c|c|c|c|c|c|c|c|c|c|c|c|c|c|c|c|}
\hline \multirow{2}{*}{$\begin{array}{l}\begin{array}{l}\text { Automo- } \\
\text { tive Pilot } \\
\text { Plans Needs }\end{array} \\
\end{array}$} & \multicolumn{8}{|c|}{ Input Data } & \multicolumn{4}{|c|}{ Objectives } & \multicolumn{5}{|c|}{ Output Data } & \multirow{2}{*}{$\begin{array}{c}\text { Algorithm } \\
\text { Type }\end{array}$} \\
\hline & $\mathrm{Id}_{1}$ & $\mathrm{Id}_{2}$ & $\mathrm{Id}_{3}$ & $\mathrm{Id}_{4}$ & $\mathrm{Id}_{5}$ & $\operatorname{Id}_{6}$ & $\mathrm{Id}_{7}$ & $\mathrm{Id}_{8}$ & $\mathrm{O}_{1}$ & $\mathrm{O}_{2}$ & $\mathrm{O}_{3}$ & $\mathrm{O}_{4}$ & $\mathrm{Od}_{1}$ & $\mathrm{Od}_{2} \mathrm{Od}_{2}$ & ${ }_{3}\left|\mathrm{Od}_{4}\right|$ & $\mathrm{Od}_{5}$ & $=\mathrm{Od}_{6}$ & \\
\hline & $X$ & $X$ & $X$ & $X$ & & $\mathrm{X}$ & $X$ & & $X$ & & & X & $\mathrm{X}$ & & & $X$ & $\mathrm{X}$ & $\begin{array}{l}\text { AO/ Stra- } \\
\text { tegic- } \\
\text { operational } \\
\text { optimisa- } \\
\text { tion }\end{array}$ \\
\hline & $X$ & X & $X$ & $X$ & $X$ & $\mathrm{X}$ & & & & & $X$ & $\mathrm{X}$ & $\mathrm{X}$ & $X$ & & $X$ & $\mathrm{X}$ & $\begin{array}{l}\mathrm{AO} / \mathrm{Sim}- \\
\text { plex }\end{array}$ \\
\hline
\end{tabular}

\section{Conclusions}

The main aim of this paper is to support manufacturing networks in the optimisation of manufacturing and logistic assets by the collaborative calculation of production plans, replenishment plans and delivery plans in order to achieve shorter delivery times, better speed and consistency of schedules, higher use of productive resources and energy savings. To study this, the needs identified by the enterprises belonging to Automotive pilot were identified in two contexts: (i) considering uniquely the computation of the production plan (Make, M), and (ii) the computation of source, make and delivery collaborative plans (SMD). On the other hand, the performed state of the art has allowed identifying how the contributions proposed in the literature cover the industrial needs, in terms of computing manufacturing and logistic plans. In this regard, a set of gaps have been found in the form of non-covered industrial optimisation needs. The non-covered needs, identified with the mapping task, must be addressed when developing, in future research, novel optimisation algorithms. The most matching optimisation algorithms found in the literature will be used as a base for the implementation of the novel algorithms, which will fulfil the needs of industrial optimisation cases.

Acknowledgement. The research leading to these results is in the frame of the "Cloud Collaborative Manufacturing Networks" (C2NET) project, which has received funding from the European Union's Horizon 2020 research and innovation programme under grant agreement No 636909

\section{References}

Alemany, M. M. E., Boj, J. J., Mula, J., \& Lario, F. C. (2010). Mathematical programming model for centralised master planning in ceramic tile supply chains. International Journal of Production Research, 48(17), 5053-5074. 
Billington, P. J., McClain, J. O., \& Thomas, L. J. (1983). Mathematical programming approaches to capacity-constrained MRP systems: Review, formulation and problem reduction. Management Science, 29(10), 1126-1141.

Chen, C.L. and Lee, W.C., 2004. Multi-objective optimization of multi-echelon supply chain networks with uncertain product demand and prices. Computers and Chemical Engineering, 28, pp. 1131-1144.

Clark, A.R., 2003. Optimization approximations for capacity constrained material requirements planning. International Journal of Production Economics, 84(2), pp. 115-131.

Escudero, L. F. (1994). CMIT, capacitated multi-level implosion tool. European Journal of Operational Research, 76(3), 511-528.

Franz, C., Hällgren, E. C., \& Koberstein, A. (2014). Resequencing orders on mixed-model assembly lines: Heuristic approaches to minimise the number of overload situations. International Journal of Production Research, 52(19), 5823-5840.

Gansterer, M. (2015). Aggregate planning and forecasting in make-to-order production systems. International Journal of Production Economics.

Giglio, D. and Minciardi, R., 2003. Modelling and optimization of multi-site production systems in supply chain networks. En Proceedings IEEE International Conference on Systems, Man and Cybernetics, vol. 3, pp. 2678-2683.

Gupta, D., \& Magnusson, T. (2005). The capacitated lot-sizing and scheduling problem with sequence-dependent setup costs and setup times. Computers \& Operations Research, 32(4), 727-747.

Hernández, J. E., Mula, J., Poler, R., \& Lyons, A. C. (2014). Collaborative planning in multi-tier supply chains supported by a negotiation-based mechanism and multi-agent system. Group Decision and Negotiation, 23(2), 235-269.

Karimi, I. A., \& McDonald, C. M. (1997). Planning and scheduling of parallel semicontinuous processes. 2. Short-term scheduling. Industrial \& Engineering Chemistry Research, 36(7), 2701-2714.

Lim, S.J., Jeong, K.S., Kim, M.W. and Park, 2005. A simulation approach for productiondistribution planning with consideration given to replenishment policies. The International Journal of Advanced Manufacturing Technology, 27, pp. 593-603.

McDonald, C. M., \& Karimi, I. A. (1997). Planning and scheduling of parallel semicontinuous processes. 1. Production planning. Industrial \& Engineering Chemistry Research, 36(7), 2691-2700.

Mula, J., Peidro, D. and Poler, R., 2010. The effectiveness of a fuzzy mathematical programming approach for supply chain production planning with fuzzy demand. International Journal of Production Economics, 128, pp. 136-143.

Mula, J., Poler, R., Garcia-Sabater, J.P. and Lario, F.C. (2006) Models for production planning under uncertainty: A review.

Noori, S., Feylizadeh, M.R., Bagherpour, M., Zorriassatine, F. and Parkin, R.M., 2008. Optimization of material requirement planning by fuzzy multi-objective linear programming. Proceedings of the Institution of Mechanical Engineers -- Part B -- Engineering Manufacture, 222(7), pp. 887-900.

Rota, K., Thierry, C., \& Bel, G. (1997). Capacity-constrained MRP system: A mathematical programming model integrating firm orders, forecasts and suppliers. Departament d'Automatique, Universite Toulouse II Le Mirail.

Sabri, E. H., \& Beamon, B. M. (2000). A multi-objective approach to simultaneous strategic and operational planning in supply chain design. Omega, 28(5), 581-598.

Supply Chain Council (2012). Supply Chain Operations Reference Model (SCOR), Supply Chain Operations Management Retrieved from: http://www.apics.org/sites/apics-supplychain-council/frameworks/scor

Yenisey, M.M., 2006. A flow-network approach for equilibrium of material requirements planning. International Journal of Production Economics, 102(2), pp. 317-332. 